\title{
Organization and Society: Understanding Corporate Social Responsibility and The Inclusive Business in The Peruvian Business Environment
}

\author{
Andrés R. Negro \\ University of the Pacific \\ Keiser University \\ Ronald Mesia \\ Florida International University
}

The concepts and terminologies that link the efforts of companies and society for poverty reduction are increasingly numerous and lend themselves to confusion, both conceptually and in their practical business applications. Terms such as inclusive innovation, inclusive business, corporate social responsibility, sustainability, and third sector-social enterprise, all, in essence, have some link between the vision of a business and its contribution to society through its management model. But in practice, that linkage does not mean that they have the same approach and objective.

The abundance of terms makes it difficult to create more dynamic progress toward the common goals established by the United Nations at the World Economic Forum in Davos (1999). These goals emphasize the relevance of collaborative contributions from the business sector for the preservation of social values and global economic progress, as well as sustainable global development.

In this work, our objective is to clarify two concepts of business management-corporate social responsibility and inclusive business-in the Peruvian Business Environment. This research is intended to generate clarity for future research that seeks to strengthen the link between business and society in Peru. We present, as an introductory framework, a brief review of scenarios related to world poverty, and, poverty in Peru.

Keywords: Inclusive Business, Corporate Social Responsibility, Peruvian Business Environment

\section{INTRODUCTORY FRAMEWORK}

\section{Global Environment and Poverty}

Poverty is defined as "the inability to achieve a minimum standard of living" (World Bank, 1990: p. 26-27). Aligned with this definition, various academic researchers, including Gutiérrez and Lobo (2006), have interpreted the concept of poverty as encountering unfavorable conditions both in capacity and in access to material resources. 
Globally, indicators suggest that the gap between poverty and wealth persists despite recent global efforts and accomplishments, as noted in the report of 2015 submitted by the United Nations (UN) on the Millennium Development Goals (MDGs). Indeed, the spectrum of poverty reduction indicators published in the last two decades reflects significant progress. For example, in 1990, 47\% of the population in developing countries lived on incomes of less than 1.25 dollars a day, however, this indicator reached to only $14 \%$ for the same population earned less than 1.25 dollars a day in 2015 (United Nations, 2015). Despite this global reduction in the number of people experiencing extreme poverty, from 1.95 billion in 1990 to 836 million in 2015, the situation remains alarming. The current economic model is not adequate to combat poverty, as described in the Nobel-winning work of Stiglitz (2000). Fisac et al. (2011) state that the current economic model has signs of unsustainability on multiple fronts, economic, social, and environmental. While it is true that governments are (theoretically) in charge of delineating policies and strategies for poverty reduction, it is no less accurate than other sectors of society, such as private citizens and private enterprise, also have a responsibility to participate in efforts toward poverty reduction ( $\mathrm{J}$. Yong Kim, 2013).

The UN's 2014 report on human development defines an indicator of "multidimensional poverty," which differs in its measurements from other indicators that measure poverty through income or consumption. This new indicator shows other elementary aspects that are consequences of poverty, the effects of which are seen in high-priority sectors such as health, food, education, and housing; these sectors are vital and thus their status provides a more realistic view of what is happening in the world.

By contrast, a report on the goals of the Millennium Development Goals (MDGs) released on July 6, 2015, through the UN News Centre, reveals that more than one billion people surpassed the threshold of extreme poverty in the world thanks to the impetus of the MDGs. This is a breakthrough, but in the same report, United Nations Secretary-General Ban Ki-moon warned the fragility of these developments and the danger of losing ground if public-private initiatives are not deepened.

In 2016, the UN released a human development brief laying out essential pillars that align with technical attributes of the concept of corporate social responsibility (CSR) and businesses that address the obstacles of exclusion from a human development perspective. It contains the need for better policies and decisions in the field of business. The report emphasizes the importance of awareness of humanity and the sectors that compose it towards achieving the objectives of sustainable development as set out in the 2030 agenda.

Nevertheless, the report warns the existence of obstacles and threats that may prevent the achievement of the MDGs. Thus, it is imperative to develop further close relationships between government and business policies that promote social progress and inclusion (United Nations, 2016). In highlighting the need for a stronger commitment to global entrepreneurship, it is aligned with Schumpeter's (1942) contributions from "Capitalism, Socialism, and Democracy."

Schumpeter emphasizes the role of private companies and entrepreneurs in particular; independent of an entrepreneur's location within the ranks of the company and in the task of economic and social transformation. Through fostering the long-term development of the creativity and capacity of the individual, companies can promote behavior toward investments that forge jobs, creating a background of social concern. He also notes the innovation capacity of private enterprise as a contributing factor for social development (Bravo, 1998; Macias, 2012). Despite the relationship between companies and society increased, this work presents an approximation for the current scenario of social responsibility of private companies to know and to interpret their roles in supporting global social objectives.

\section{Peru's Business Environment and Poverty}

Over the period 2011-2015, Peru has experienced macroeconomic growth of the order of four to six percent of gross domestic product (GDP; World Bank, 2016). It's GDP, on average, was higher than that in the Latin American region and the Caribbean as a whole (4.7\% vs. 2.4\%, over the same period; Presidency of the Council of Ministers of Peru-PCM 2016). This growth did not solve the problems of inequality in terms of the generation of opportunities for sustainable development for the portion of the population at "the base of the pyramid"; a term coined by Prahalad and Hammond (2002).

Journal of Applied Business and Economics Vol. 21(5) 2019155 
According to data from the World Bank (WB; 2016), the growth of the per-capita gross domestic product of Peru described a downward curve from 2010-2014, as shown in Figure I. As the WB explains, this indicator reflects the annual percentage growth rate of GDP per capita in a country's local currency. It is necessary to monitor this indicator, as it could reveal stagnation in the process of continued development.

\section{FIGURE 1 \\ ANNUAL AVERAGE PERCENTAGE OF GROWTH DOMESTIC PRODUCT (GDP) PER CAPITA IN PERU - 1990-2004 (\%)}

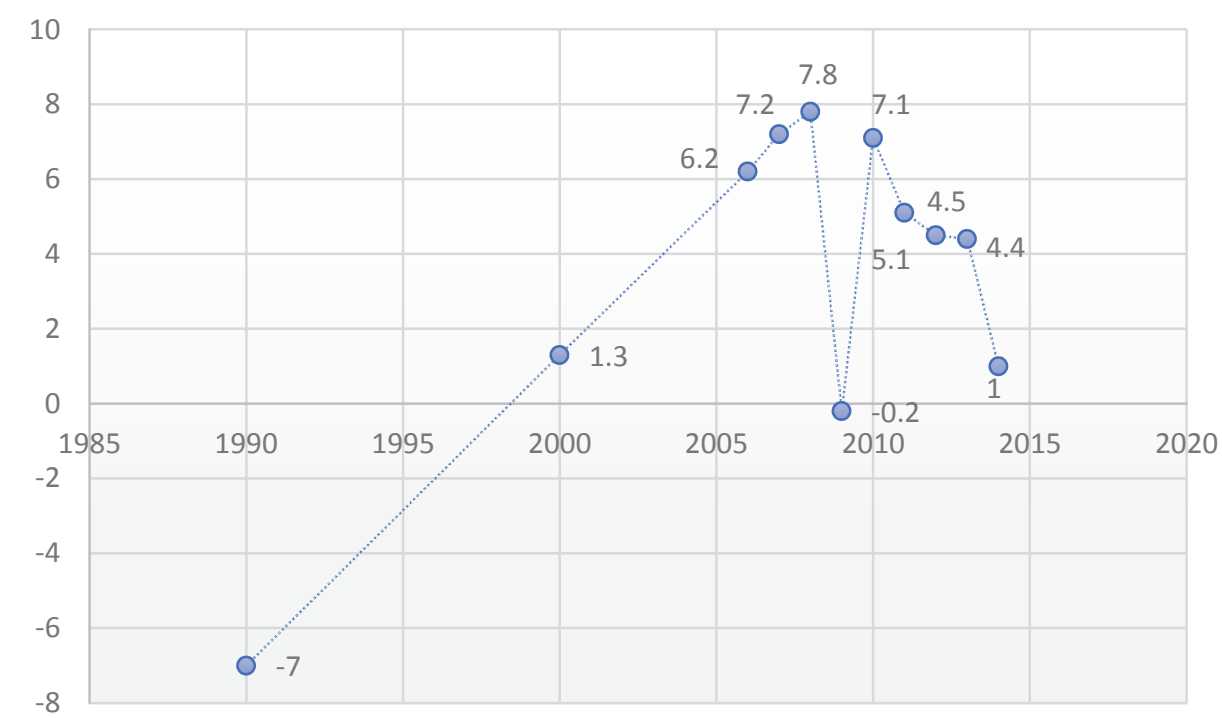

Source: Data-World Bank (2016)

The annual Percentage rate of Gross Domestic Product (GDP) per capita in local currency GDP per capita is the gross domestic product divided by the mid-year population.

However, according to data published by the National Institute of Statistics and Informatics of Peru in 2016, the incidence of poverty has decreased in the last ten years (2007-2016), down to 28.4 percentage points. In comparison with rural areas, the prevalence of poverty was reduced by 1.4 percentage points in 2015-2016, which means $43.8 \%$ of the rural population was still in poverty. In urban areas, only $13.9 \%$ of the population was affected by poverty. Thus, 264,000 people escaped poverty in 2016 (INEI 2016). The most recent general figures on poverty in Peru suggest $20.7 \%$ of the population affected by poverty. This means $6,518,000$ people, out of a total population of approximately 31.5 million, was spoiled by poverty, as of 2016 (INEI 2016). These positive figures which indicated social progress among the population and reduced poverty should be reflected in the creation of a stronger framework of social and economic policies to encourage sustainable growth among Peru's poorest people. These policies should not be a short-term commitment allocated by the government but represent a public-private partnership. Although many people have recently escaped from poverty, the population of rural areas in Peru is still more likely to live in poverty (43.8\%). Thus, it is particularly essential to conduct constant monitoring of progress among people that recently escaped from poverty in rural areas to avoid setbacks in ongoing efforts to reduce poverty.

The government is one of the decision bodies responsible for providing an environment that offers substantial opportunities and providing long-term vision. This is best done through the generation of social and economic policies with a vision of sustainability, as emphasized by Yamada (2015). In Peru, there is a segment of the population living between the level of the middle class and poverty, called the 
"vulnerable class"; unless further economic opportunities are made available, members of this vulnerable class are at risk of falling back into poverty.

The contribution which alerts you cannot fall into triumphalism that becomes mirages when global economic and political events affect the economy of the country and social setbacks manifest as a consequence. The support and intervention from the private sector are paramount to collaborating for such social progress; it is necessary to fight poverty to provide knowledge and resources in order to generate profitable new businesses with positive social impact (Mizruchi, 1990; Bruni, J. González, A. 2010).

Sanborn et al. (2013) suggest "hidden poverty" (p. 24) exists within the social spectrum of Peru. They propose a vision of measuring poverty using a multidimensional approach and index, as described in UN Human Development Reports (2014 and 2016). The indicators in such an index should be drawn from high-priority sectors such as health, food, education, and housing to reflect more accurately the effects of poverty. In their analysis, Sanborn and coworkers include the aspect of changes in the management of support or social investment by prioritizing a multidimensional approach to poverty. This approach prioritizes needs to be covered based on those essential services where both governmental and private support is adequate. This implies a change of mindset and direction of resource management. Thus, according to Sanborn et al. (2013), the change of management could, in principle, result in a new structure with existentialist traits, but in a relatively short time, it becomes a medium- and long-term selfsustaining support structure.

Nevertheless, the reality is different; social policies developed in this way have a high degree of bias toward immediate welfare without the prospect of self-sustainability in the medium- and long-term range. Government promoters respond to a clear and defined strategy (Trivelli, C. 2015), which is not appreciated with the clarity and contrasts with the manifestation of private business representatives. The first is the concept of "grow to include" (Abusada, R. 2015) which is different from a welfare approach.

Jiménez (2009) refers to social policy as a set of actions promoted by the political actors of a country, whose objective is to improve the opportunities, the distribution, and accessibility of goods and services for some part of the population. Despite progress in reducing the levels of poverty in Peru, these approaches are insufficient, and cannot continue to be the primary mechanisms for the reduction of the poverty, but it could be proposed as an associate approach to reduce the poverty. Poverty produces an environment of increased vulnerability; as seen in the figures presented by the INEI (2016- Figure 2). This result indicates that $43.8 \%$ of the rural population of Peru remains in poverty, three times more than the rate of urban poverty $(13.9 \%)$. 
FIGURE 2

POVERTY RATE BASED ON THE NATIONAL POVERTY LINE IN PERU (2001-2014)

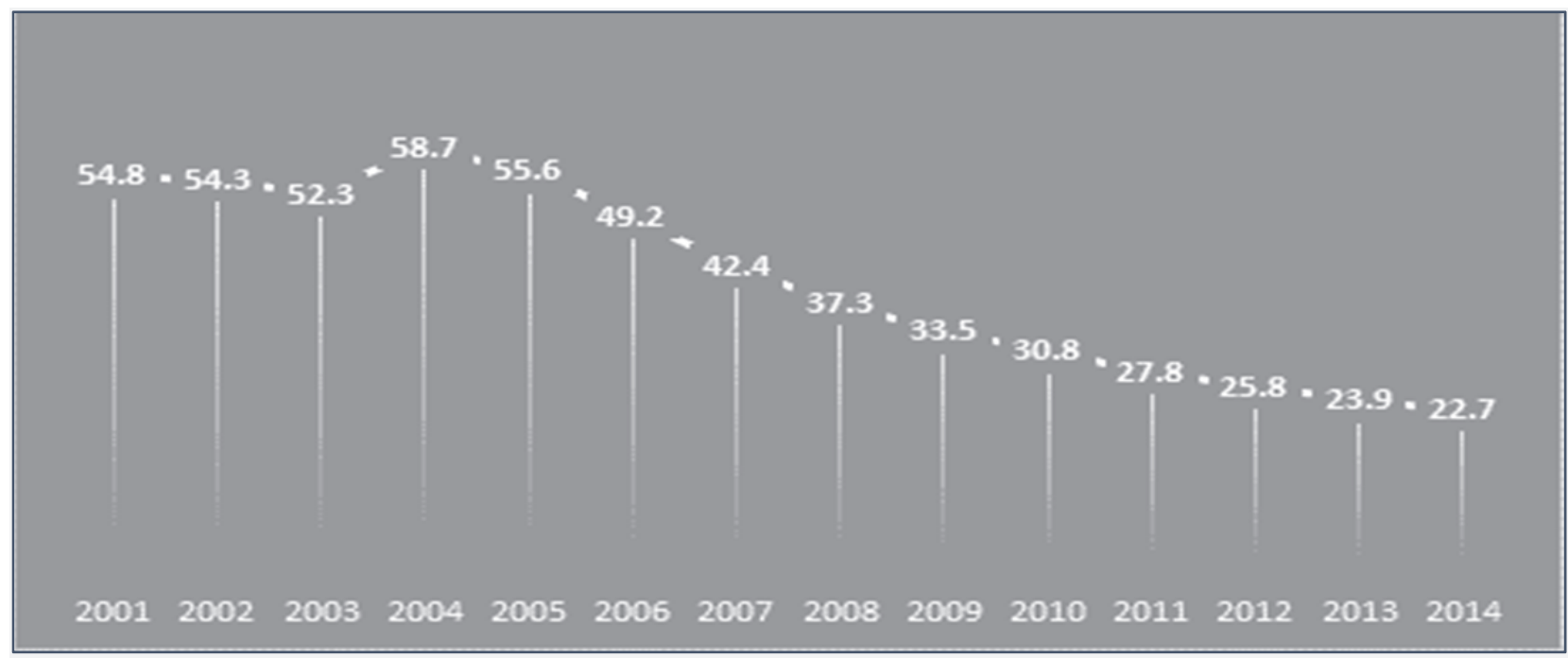

Source: Data-World Bank (2016)

The rate of incidence of poverty is the percentage of the population living below the national poverty lines. National estimates are based on estimates of weighted population subgroups from household surveys.

These positive figures which indicate social progress among the population and reduced poverty should be reflected in the creation of a stronger framework of social and economic policies to encourage sustainable growth among Peru's poorest people. This framework should not be a short-term commitment assigned by the government but represents a public-private partnership.

\section{Relationship Between Poverty, Inclusive Business and Social Reliabilities}

The brief review of the global and local approaches to addressing poverty in a developing countryin this case, Peru - was introduced in the introduction of this article. This review is intended to serve as a basis for approaching business concepts and strategies that contribute to poverty reduction. The development of such thoughts and plans is the first of the sustainable development goals of the United Nations Global Agenda for 2030. Concepts and procedures such as general business, which aligns with CSR approaches on the part of private entrepreneurship, can generate what Prahalad (2005) described as the transformation of vulnerable situations of resource scarcity into development opportunities. In what follows, we present a practical example of the development of a general business operating under CSR best practices in Peru.

\section{Case: The Sustainable Development Model of Alicorp S.A. (Grupo Romero)}

Alicorp implemented sustainable good practices in the value chain of all its products by involving all stakeholders that had an essential role in its supply chain. The production chain selected for exploration was in agriculture, through its Quinoa product, "Kuska".

\section{Details of the Inclusive Business Project with a Focus on Social Responsibility}

Alicorp developed its production chain for Kuska in El Pedregal (Arequipa) in 2013, with a focus on growing the industry and improving the quality of its products.

- The program was centered in El Pedregal, Majes, Arequipa.

- The important stakeholders in this project were all individuals involved in the productive and distributive chain of the product. However, the most deeply involved ones for the purpose of this business were more than 130 farmers, their families, and their community. 
- As a customer of small farmers, Alicorp offers consulting services by incorporating both technical and farming supervision to improve product quality and production efficiency. As part of this initiative, farmers were separated into groups called "seeding modules" and assigned to consultants who were commissioned by each of these groups to give them the support.

- There is also a "loyalty program" which consists of field visits, training, recognition bonds, and awards to farmers for an excellent performance.

- Alicorp S. A. financially supported this project.

\section{Identification of Dual-value Results (Business and Social Impacts)}

The present summary demonstrates the integration of Peruvian poor people into the value chain of a corporation by aiming to generate social and business value; an approach that is different from assistance or philanthropy. Opening up to new tools (e.g., media or technologies) may enable low-income people to take a big step toward improving their lives (Prahalad, 2005)

- The productivity of the communities increased due to support from Alicorp. This support permitted the formation of better social and business organization.

- Farmers were able to learn better cultivation techniques due to the advice they received. These instructions helped them to be more efficient with the time they spent working; thus, they quickly produced a better product with higher quality which made it more competitive.

- In 2013, with the help of the loyalty program, Alicorp achieved $74 \%$ effectiveness with the planting modules.

- The higher incomes that the farmers received allowed them to have a better quality of life.

- This collaborative process allowed the communities involved to have greater access to different products to help them improve their day-to-day lives. This process resulted in a higher capacity to work due to improvements in their physical and mental health.

The case outlined above helps us to identify the objective of the application of the terms of Inclusive Business and CSR in business projects. This new concept goes beyond philanthropic action and attempts to generate a strategic alliance that benefits both parties. This case supports an appreciation of the conceptual aspects of the terms inclusive business and CSR.

\section{BUSINESS MANAGEMENT TERMS TO REVIEW}

\section{Inclusive Business}

Inclusive business is a business model that started in the Latin American business community (Márquez, Reficco and Berger, 2009). The methodology is defined by Ishikawa and Strandberg (2009) as a business model in which business profitability is aligned with a sustainable social transformation to contribute to poverty reduction via private initiatives. Contrary to the traditional paternalistic, welfare and philanthropic overtones of supportive actions, such as corporate social assistance aimed at low-income people, it provides opportunities and tools for personal, social, and financial growth within the community by converting corporate profit into an instrument of value creation and social transformation. In this formulation, we emphasize two concepts that have been propagated more than over a decade, according to Prahalad and Hammond (2002). These concepts include the participation of the private sector and the creation of dual value (enterprise and society) through a business model rather than via assistance.

Along this conceptual line, Licandro O. (2013) mentions that market economies are fertile ground to develop employment opportunities for members of the low-income sector, either as employees or as micro-entrepreneurs integrated into supply chains. A unique aspect behind this business model is that it improves the standard of living in the target community by consuming the product and services generated within the community. 
One of the essential elements of inclusive business is the participation of the private sector (as discussed above). Therefore, it is necessary that entrepreneurs and executives who direct private entrepreneurship incorporate features that generate social benefit into their analyses and business strategies, particularly in rural and urban societies that are potential markets in the medium and long term. Strategies that strengthens the position of potential new buyers promote social development and as a natural consequence maximizes shareholder value. Therefore, implementing innovative business models deliver sustainable development for a community.

What Chu (2010) calls the dual development space of "simultaneous creation of social impact and commercial value" (p. 26) can be described by an example from the micro-finance sector. Managing and decreasing cultural distances between business, its managers, and members of low-income populations with different customs and types of organization is vital. For example, the case in the agro-industrial sector studied by Ickis et al. (2009) demonstrates the ignorance of the distance and distrust between the two parties.

\section{Corporate Social Responsibility}

The concept of corporate social responsibility (CSR), initially developed in the 1970s, arises from the seminal work of Friedman (1970). Friedman's conception, from the perspective of business competitiveness, states that the primary responsibility of a company is to obtain financial profits. Velez (2010) interprets that work as providing an intellectual position that offers a sole, overriding responsibility for business management: the responsibility to give the shareholders the maximum economic benefit (assuming the business is performed within basic legal and ethical parameters). From this point of view, social advancement is considered a purely governmental responsibility (CRESPO 2010). For the conceptual advancement of CSR, the major theoretical studies oppose this viewpoint and focus on developing positive relationships between companies and society. However, it provides an approach with a greater emphasis on a paradigm shift from a broader perspective. This has led to exciting contributions, like that made by Arrow (1973), who focuses on CSR as part of a necessary panorama of management strategies for organizations. This is in contrary to Friedman's position by rejecting profit as the only aspect that affects competitiveness.

In more recent years, Bruni and Gonzalez (2010) have defined corporate social responsibility as " a broad concept that refers to the integration, on the part of companies, of social and environmental concerns in their operations and in relations with their interlocutors "(p. 14). Subsequently, academic contributions made in the 1980s built upon the stakeholder-centered theories of Freeman and Reed (1983).

Alvarado, Bigné, and Currás (2011) emphasize that this contribution entrenches the dual-lens through which we should consider an enterprise manager. This view possesses responsibilities to shareholders (to provide profits) as well as towards the enterprise's network of employees and community members that contribute to or are linked by the business processes of the company. Freeman and Reed's (1983) work provided an underlying theory to support the concept of CSR by aligning the company and the individuals with which they interrelate via common points of interest.

This simple definition has received criticism from the business community; for instance, the obligation of CSR on the business sector is usually taken superficially and not with an appropriate vision for a business, whose primary objective is to generate profitability and dividends for its shareholders (Crook, C., 2005). It is also evident in the discrepancy expressed in a comment from Soros (Quoted by Pérez, F. and Cordero, A., 2010) by recommending that social responsibility is a false form of management.

Although there are different viewpoints on the CSR, the work of Schwalb and García (2003) highlighted the importance of the CSR in the academic and business by what they call the "triple motivation: community, society, and company" (p. 74) under a favorable and integral perspective of progress and advancement. 


\section{Confusion in the Peruvian Business Scenario}

Many authors (e.g. Reficco, E. \& Ogliastri, E., 2009; Brunni, J, Gonzalez, A. \& Gomez, H., 2009; Reficco, E. 2010), have shown that it is straightforward to be confused by and about the current terminology for business visions related to collaborative commitments to reduce poverty. Specifically, concerning general businesses, Piñango (2010) suggests that the concept is often confused with the concepts of CSR and "modern philanthropy" (p. 1). Moura and Padgett (2014) state that this creates confusion about strategic applications among business executives.

Hindering the central objective of helping to reduce poverty sustainably and profitably from a private business perspective, the inclusive business model is, in its conception and its practical application, the opposite of nonprofit management. FOMIN report (2015) highlights that the essence of the inclusive business model is to converge on dual-value creation strategies by creating business opportunities that work for both the business and the low-income sector.

Peruvian entrepreneurship is not oblivious to these points of confusion, which slow or prevent the implementation and application of inclusive business models and limit consideration of social alignment at the same level of importance given to the core business of organizations with a long-term mentality.

There is still much to be done in this area. The Netherlands Development Organization, the leading international organization, promoting inclusive business in Peru, reported only 26 such projects (This report, revised in June 2014, was retrieved from the virtual portal of the SNV, but is no longer available). The projects listed were created by businesses such as Rainforest Expeditions (tourism sector), Condor Travel (tourism sector), and Dole (agricultural industry). These projects are the same as those reported by Segovia (2009). This small number of projects is in contrast with 1,883,531 companies registered at the national level in Peru in 2014 (INEI 2015). Thus, the percentages are shown in Table I make it clear that the pyramid of the country's entrepreneurial sector relies on a foundation of the micro-enterprise industry. This situation exposes the economy of Peru to a high degree of vulnerability to internal and external events that resulted from macro-economic policies.

TABLE 1 DISTRIBUTION OF COMPANIES IN PERU - 2014

\begin{tabular}{|l|l|}
\hline $0.36 \%(6,791$ companies $)$ & Public administration \\
\hline $0.60 \%(11,380$ companies $)$ & $\begin{array}{l}\text { Medium and large } \\
\text { businesses }\end{array}$ \\
\hline $4.11 \%(77,503$ companies $)$ & Small business \\
\hline $94.9 \%(1,787,857$ companies $)$ & Micro-business \\
\hline
\end{tabular}

Source: INEI - Peru, 2015

CSR is generally considered as an entrepreneurial act of good intentions by the private sector (social marketing), against a background of an institutional image and cultivating a good reputation, as mentioned above. From this perspective, there is another source of confusion; CSR is bigger than reputation or institutional image. CSR is a model of sustainable management in which the different interest groups that participate in business can be aligned to act responsibly and ethically in promoting the advancement of one of the main objectives of the Sustainable Development Global (United Nations 2015) by eradication of poverty. This is far from a short-term welfare perspective.

There is still much to be done in promoting these models as tools of business management in Peru. In the 5th Edition (2015) of the socially responsible company (ESR $\left.{ }^{\circledR}\right)$ awards for Peru 2021, the leading promoter organization of CSR in the country meets one or more requirements for social responsibility programs out of the eight categories considered requirements for that classification. It is reported that only fifty-five companies from 18 economic sectors were listed as being considered socially responsible. All of 
these companies constitute only $0.6 \%$ of the total companies registered in Peru in 2014 and represented the sector of medium and large companies (Table I).

\section{CONCLUSION}

The primary conclusion of this article is that both corporate social responsibility and inclusive business often generate short term positive reputation which is intangible profits for companies. For this reason, companies tend to consider them as marketing tools instead of striving to develop and implement such programs on a larger scale.

Increased awareness will help business leaders incorporate within their entrepreneurial mindset the need to forge a close relationship between financial and social profitability as a possible market link. This objective will be achieved based on well-defined concepts, their dissemination, and their replication at the same level when new challenges or strategies are met within the business of an organization. This is seen in the example of the Romero group through its subsidiary, Alicorp, and its product, Kuska Quinoa. The success of this general business format that incorporates social responsibility shows that the private sector also has a social commitment and can contribute to the enormous task of reducing poverty.

Replicating this model to develop other examples of relationships between private companies and society will consolidate the Peruvian middle class, and contribute to the advancement of the low-income sector of Peru. In contrast to an assistance approach which becomes less effective over time, this approach offers a long-term vision for sustainability. We recommend the future work focuses on developing and understanding the best practices for implementing revised management tools and models.

\section{REFERENCES}

Abusada, R. (2015, August 2). Government Palace played against the private investment. (M. Balbi, interviewer)

Alicorp, S.A.A. (2013). Sustainability report.

Alvarado, A., Bigne, E., \& Curras, R. (2011). Theoritical perspectives used for the study of CSR: A classification based on its rationality. Management Studies, 27(118), 115-137.

Arrow, K. (1973). Social responsability and economic efficiency. Public Policy, 21(3), 303 - 317.

Bravo, E. (1998). Revision of the concept of Entrepreneur: an exploration of the contributions of Keynes and Schumpeter. Management and organization, 20, 16-23.

Bruni Celli, J., \& Amelia González, R. (2010). Successful business with social impact. Debates IESA, 15(3), 14-19.

Bruni, J., González, R., \& Gomez, H. (2009). Big companies and SMEs as social entrepreneurs. Harvard Business Review Latin America, 87(5).

Chu, M. (2010). Microfinance simultaneous creation of Impact to social and commercial value. Debates IESA, 15(3), 26-30.

Crespo, F. (2010). Between the concept and the practical: Corporate social responsibility.Management Studies, 26(117), 119-130.

Crook, C. (2005, January 20). The good company. (T. Economist, Interviewer)

Dutch development cooperation service. (2014). SNV Perú. Retrieved from http://www.snvworld.org/en/countries/peru

Fisac, R., Moreno, A., Mataix, C., \& Palacios, M. (2011). The social enterprise: Revision de Concepts and model for organizational analysis. Spain Magazine wave of the third Sector.

Fomin - SNV Ford fundation. (2015). Transforming the relations of Business-inclusive business into Latin America's rich loved. Washington, DC: Inter-American Development Bank. Office of the Multilateral Investment Fund.

162 Journal of Applied Business and Economics Vol. 21(5) 2019 
Freeman, E., \& Reed, D. (1983). Stockholders and Stackeholders: A new perspective on corporate governance. California Management Review, 25(3), 88 - 106.

Friedman, M. (1970, September 13). The social responsability of business is to increase its profits. The New York Times Magazine.

Friedman, M. (2007). The social responsability of business is to increase its profits. En W. Zimmerli, M. Holzinger, \& K. Richter, Corporate ethics and corporate governance (págs. 173 - 178). Springer Berlin Heidelberg.

Gutiérrez, R., \& Lobo, I. (2006). Is it possible to alleviate poverty through business? Harward Review of Latin America, VI (1), 39-41.

Ickis, J., Leguizamón, F., Metzger, M., \& Flores, J. (2009). Agroindustry: Fertile field for inclusive businesses.Academia, Latin American Magazine of administration, 43, 107-124.

Ishikawa, L., \& Strandberg, L. (2009). Inclusive business: Creating value for companies and for population of low resources.La Caixa Chair of Social responsibility of the company and corporate governance IESE business School, University of Navarra.

Jiménez, I. (2009). Social policies and poverty reduction. The challengeor Peruvian. Academy Repository Postgraduate School Universidad Peruvian Applied Sciences, 1-13.

Licandro, O. (2013). Models for Análysis of inclusive businesses: Construction through case studies.Telos. Journal of Interdisciplinary Studies in Social sciences, 15(1), 32-48.

Macías, H. (2012). Innovation and social Responsibility: a reflection on the meeting points. University and Business, 13(21), 13-35.

Marquez, P., Reficco, E., \& Berger, G. (2009). Inclusive business in Latin America's. Harvard Business Review, 28-38.

Mizruchi, M. (1990). Cohesion structural equivalence and similarity of behavior: An Approach to the study of corporate politica power. Sociological Theory, 8, 16 - 32.

Moura, R., \& Padgett, R. (2014). The evolution of corporate social responsibility: a historical approach. Espacios 35 Magazine (5).

National Institute of Statistics and Informatics of Peru. (2016). Poverty figures. Retrieved from http://www.inei.gob.pe/cifras-de-pobreza/

National Institute of Statistics and Informatics of Peru. (2015). Peru: Business structure 2014.Lima: INEI.

Ogliastri, E., \& Reficco, E. (2009). Company and Society in America Latina. Magazine Latin American AdministrationN, 43, 1-198.

Pacific University - Press room. (2015). Gustavo Yamada: "Being of middle class would cost more expensive in Peru. Retrieved from www.up.edu.pe/prensa/gustavo-yamada-ser-clase-media-4065

Pérez, F., \& Cordero, A. (2010). New regional view of CSR. INCAE Business Review, 1 (10), 34-35.

Peru 2021. (2016). Peru 2021 First Social responsibility Portal of Peru. Retrieved from http://www.peru2021.org/principal

Piñango, R. (2010). Editorial: Inclusive Business-a new paradigm. IESA Debate.

Prahalad, C., \& Hammond, A. (2002). Serving the world's poor, profitably. Harvard business review, 80(9).

Pralahad, C. (2005). Development as a social transformation. In C. Pralahad, the business opportunity at the base of the pyramid.

President of The Council of Ministers of Peru. (2016). Informe Pre-Electoral administration 2011-2016. Lima: The Peruvian.

Reficco, E. (2010). Inclusive Business and social responsability . Debates IESA, 15(3), 20-24.

Roman, L. (2001).Conceptions of politics structural adjustment policies. Mexico: Home Mexico.

Romero Group. (2013). Annual report. Generating pride-Grupo Romero: www.gruporomero.com.pe 
Sanborn, C., Bonifaz, J., Casas, C., Seminario, B., Urrunaga, R., Vásquez, E.; Yamada, G; Zegarra, M. (2013). Peru towards 2062: Thinking together the future. University of the Pacific-Research Centre-Discussion Paper.

Schwalb, M., \& García, E. (2003). Evolution of the social commitment of the companies.Research Center of the University of Pacifico-Peru, 58, 1-95.

Segovia, L. (2009, October 30). SNV increases in more than 50\% inclusive business projects in 2009. (R. S. Sustainability, interviewer)

Stiglitz, J. (2000). Capital market liberalization, economic growth, and instability. World Development, 28(6), $1075-1086$.

Trivelli, C. (2015, August 2). Social programs respond to clear and definite strategy. (Trade, interviewer).

United Nations. (2014). Human Development Report 2014-Sustaining human progress: reducing vulnerabilities and building resilience. United Nations Development Programme.

United Nations. (2014). Message of the Secretary-General of the United Nations.Retrieved from http://www.un.org/es/events/socialjusticeday/2014/sgmessage.shtml

United Nations. (2015). Millennium Development Goals Report of 2015.New York: United Nations.

United Nations. (2015). More than a billion people came out of extreme poverty thanks to the MDGS. UN News Center.

United Nations. (2016). Human development report.New York: United Nations Development Program.

Velez, A. (2010). A response to the social action of profitability to corporate social responsibility. Journal of Sciences Strategic, 18(23), 11-25.

World Bank. (1990). World Development Report 1990: Poverty. Washington, DC. USA.

World Bank - Jim Yong Kim-president. (2013). A goal within our reach. A poverty-free world. Georgetown University. Washington, DC, USA.

World Bank. (2014, April). Peru Overview. Retrieved from http://www.bancomundial.org/es/country/peru/overview

World Bank. (2015). Data-countries. Retrieved from http://datos.bancomundial.org/indicador/NY.GDP.PCAP.CD 